\begin{tabular}{|c|c|c|}
\hline & Int.J.Curr.Microbiol.App.Sci (2021) 10(10): 558-564 & \\
\hline & $\begin{array}{l}\text { International Journal of Current Microbiology and Applied Sciences } \\
\text { ISSN: 2319-7706 Volume } 10 \text { Number } \mathbf{1 0}(\mathbf{2 0 2 1 )} \\
\text { Journal homepage: } \underline{\text { http://www.ijcmas.com }}\end{array}$ & 30 \\
\hline $\begin{array}{l}\text { EXCELLENT } \\
\text { PUBLISHERS }\end{array}$ & & \\
\hline
\end{tabular}

\title{
Study on Microbial Contamination of Mobile Phones and their Role in Nosocomial Infections in a Tertiary Care Hospital
}

\author{
Arjun Gajananrao Jadhav ${ }^{1 *}$, Sanjay More ${ }^{2}$ and Sandeep Nilekar ${ }^{1}$ \\ ${ }^{1}$ Department of Microbiology, SRTR GMC Ambajogai, India \\ ${ }^{2}$ Department of Microbiology, DR.SC GMC Nanded, India \\ *Corresponding author
}

\section{A B S T R A C T}

\section{Keywords}

Telecommunication, mobile phones, bearable electronic devices

Article Info

Accepted:

18 September 2021 Available Online: 10 October 2021
Mobile phones have become an essential part of everyday life in both healthcare and community settings. However, the widespread use of mobile phones in healthcare facilities is of concern because they can act as vehicles for transmitting pathogenic bacteria. This study aimed to investigate the bacterial contamination of mobile phones of healthcare workers (HCWs Materials and Methods: This cross-sectional study, from May to June 2018, involved 100 HCWs. The mobile phones of HCWs were swabbed for culture and antimicrobial susceptibility testing. Results: The overall prevalence of mobile phone contamination was $91 \%$. The predominant isolates were coagulase-negative staphylococci (32.65\%), Staphylococcus aureus (17\%) and Bacillus spp. (11.56\%). Other isolates were Micrococcus, Diptheroids, Enterococcus faecalis, Acinetobacter spp., Pseudomonas spp.,E.coli, Klebsiella sp. Most Grampositive organisms isolates were susceptible to Linezolid, vancomycin while most of Gram-negative organisms were susceptible to piperacillin Tazobactam, Imipenam. Meticillin resistance was detected in $24 \%$ and $22.91 \%$ of S. aureus and coagulase negative staphylococci isolates, respectively. Conclusion: Mobile phones of HCWs carry potentially pathogenic bacteria and can be a source of healthcare-associated infections in healthcare settings. Hence, regulations regarding the use of mobile phones need to be developed, especially in critical areas, to reduce the dissemination of pathogenic bacteria from hands to phones and, potentially, to patients.

\section{Introduction}

For individual telecommunication, mobile phones are long range, bearable electronic devices that are radically becoming an essential means of communication worldwide and are common, beneficial and user friendly (Debnath et al., 2018). Mobile phones are popular with healthcare workers (HCWs) and patients alike, with approximately $98 \%$ of HCWs owning a mobile phone and $84.5 \%$ bringing them to work every day (Ramesh $e t$ al., 2008) (Rana et al., 2013) (Brady et al., 2006). The constant use of mobile phones by HCWs and the lack of disinfection make them possible routes for transmission of bacterial 
pathogens, including multi-drug-resistant organisms (Famurewa et al., 2009), (Banawas et al., 2018). The mobile phones of HCWs can serve as reservoirs of healthcare associated pathogens and other organisms, particularly bacteria associated with skin colonization, due to the moisture and ideal temperature of the human body, particularly the palms of the hands. These factors, and the heat generated by mobile phones, contribute to harbouring bacteria on the device. In addition, these bacterial organisms can survive on inanimate surfaces for weeks. Hence, mobile phones may cause microbial cross-contamination between HCWs and patients, and may be a source of healthcare-acquired infections (HAIs). HAIs are a common threat to patient safety throughout the world, especially in lowand middle-income countries, as they lead to substantial morbidity, mortality and increased healthcare costs (Mushabati et al., 2021).

Studies in different parts of India show that predominant organisms isolated from contaminated cell phones are Coagulase negative Staphylococci (CoNS) followed by Staphylococcus aureus, Escherichia coli, Klebsiella pneumoniae, Acinetobacter sp, Enterococcus faecalis, and Pseudomonas aeruginosa. Multidrug resistant strains were isolated from mobile phones including Methicillin resistant Staphylococcus aureus (MRSA) and Extended spectrum beta lactamases producing organisms (ESBL), high-level aminoglycoside-resistant Enterococcus sp, and carbapenem-resistant Acinetobacter baumanii. But most of the health - professionals are not aware of the fact (Pal et al., 2015). A mobile phone can harbour more microorganisms than a man's lavatory seat, the sole of a shoe, or a door handle (Debnath et al., 2018).

Therefore, we investigated bacterial contamination of on mobile phones used by HCWs, as well the antibiotic resistance pattern of isolated microorganisms.

\section{Materials and Methods}

A hospital based cross sectional study was conducted in a rural tertiary care hospital of Maharashtra during the months of May and June 2018. A total of 100 cell phones were sampled from doctors working in the hospital. After getting informed consent, sterile swab moistened with sterile normal saline were used to swab various surfaces of the cell phones. The swabs were placed in properly tagged sterile containers (serial number, source) and then with a properly filled case record form were brought to the bacteriology laboratory for analysis. The swabs were inoculated on a plate of Blood agar media \& Mac Conkey's agar media (Hi-Media Laboratories). The plates were incubated aerobically at $37^{\circ} \mathrm{C}$ for 24 hrs. The colonies were identified phenotypically by gram staining, motility and biochemical tests as per standard protocol (Washington Winn Jr et al., 2006).Antibiotic sensitivity test of pathogenic bacteria was done by modified Kirby Bauer Disc Diffusion method on Muller Hinton's media with proper standardization by ATCC control strains (Escherichia coli - ATCC 25922; Staphylococcus aureus - ATCC 25923; MRSA - ATCC 43300, Enterococcus faecalis - ATCC 29212; Pseudomonas aeruginosaATCC 27853) (CLSI 2018).Following Antibiotic discs, containing measured and standard amount of antibiotics (procured from Hi Media) were used for drug testing.

Amikacin (AK), Erythromycin (E), Tetracycline (T), Gentamicin (GEN), Ceftriaxone (CTR), Cefotaxime (CTX), Cefoxitin (CX), Clindamycin (CD), Ciprofloxacin (CIP), Vancomycin (VA), Cotrimoxazole (COT), Linezolid (Lz), Vancomycin (V), Cefepime (CEP), Imipenam, Piperacillin Tazobactam (PIT). 


\section{Results and Discussion}

Out of 100 cell phones sampled 91 were found contaminated with varied numbers of bacteria. $47 \%$ cell phones had single bacterial contamination while $44 \%$ cell phones were contaminated with two or more types of bacteria. Total 147 bacteria were isolated, comprising of 12 species. Of which 118 $(80.27 \%)$ were gram positive organism and 29 $(19.72 \%)$ were gram negative. The most commonly isolated organism was Coagulasenegative Staphylococcus (N=48, 34.69\%) followed by Staphylococcus aureus $(\mathrm{N}=25$, $17 \%)$, Micrococcus sp ( $\mathrm{N}=15,10.2 \%)$, Bacillus $(\mathrm{N}=17,11.56 \%)$, Pseudomonas sp $(\mathrm{N}=12$, $8.16 \%)$ Diphtheroid $(\mathrm{N}=6, \quad 4.08 \%)$, Acinetobacter sp. (N=9\%, 6.12\%) E.coli $(\mathrm{N}=4,2.72 \%) \quad$ Kleb $\operatorname{spp}(\mathrm{N}=2,1.3 \%)$, etc. (Table01). 38.77\% (57/147) mobiles sampled, presented with bacteria that are established nosocomial pathogens like Staphylococcus aureus, Enterococci, Pseudomonas, Acinetobacter, Escherichia coli and Klebsiella sp whereas $33.34 \%$ were potential pathogen like Staphylococcus epidermidis. Differences in rate of contamination of cell phones are not significant in male and female individuals (Table:02). 17\% health care personnel were totally not aware of the fact that microorganisms could be present in cell phones. 94\% health professionals never even thought of cleaning their cell phones. Out of 25 Staphylococcus aureus, 6 (24\%) were methicillin resistant (MRSA), but among coagulase negative Staphylococcus 11 were resistant to cefoxitin (Table:03). Resistant pattern of gram negative organisms was shown in (Table:04).

Out of the total 100 cell phones sampled, 91 were found contaminated with varying number of bacteria. Incidence of contamination in our study was less than that of the studies by Tagore et al., (2011), Bisht $e t$ al., (2018), Shah et al., (2019) where 100\%,
99\%, 96\% cell phones were contaminated respectively but it was more than that were observed by Sharma, et al., (60\%) (Sharma, et al., 2017), Debnath, et al., (69\%) (Debnath, et al., 2018), Dutta et al., (72\%) (Datta, et al., 2009) Mushabati et al., (79\%) (Mushabati et al., 2021) Wide range of variation might be due to difference in awareness regarding usage of mobile phones, maintaining hand hygiene and frequency of handling cell phones in hospital during patient care. In the present study $44 \%$ cell phones had polymicrobial growth which was in concordance with that isolated by $\mathrm{Pal} \mathrm{K}$ et al., (Pal K et al., 2015) but it shows contrast to a study conducted by Tagore D N et al., (Tagore D N et al., 2011), where $91 \%$ of cell phones showed polymicrobial growth. In the current study, CONS (32.65\%) was the main organism isolated. Similar results were observed in different studies Pattnaik S et al., (Pattnaik S et al., 2014) Pal K et al., (Pal K et al., 2015) Mushabati et al., (Mushabati N. A et al., 2021), Shah P D et al., (Shah P D et al., 2019) Predominance of CoNS reflects the fact that CoNS normal commensal of the skin relatively harmless in otherwise healthy individuals can easily be transferred to the object that comes in contact with body surface. Combination of constant handling and heat generated during receiving phone call might facilitate the survival and growth of the microorganisms on the cell phone surface (Pal et al., 2015). However, they have been implicated in several HAIs, such as bacteraemia in immunocompromised patients, neonates, and surgical wound infections in patients with implanted valve prosthetic devices and catheters Additionally, CoNS have been shown to resist drying (they can remain viable for months on inanimate surfaces), and can multiply rapidly in warm environments (Mushabati et al., 2021). In contrast, studies in Sharma K et al., (Sharma et al., 2017), Shah et al., (Shah et al., 2019), Debnath et al., (Debnath et al., 2018) revealed 
that Staphylococcus aureus was the predominant organism. The isolation rate of $S$. aureus (17\%) from mobile phones of HCWs was in line with other studies by Mushabati et al., (Mushabati et al., 2021) which reported rates of $24 \%$ and $14.07 \%$ by $\mathrm{Pal}$ et al., (2015) $S$. aureus is frequently carried by healthy individuals on the skin and mucous membranes. (Bodena et al., 2019) (Chakolwa et al., 2019). Carriers serve as a source of infection to themselves and others; for example, by direct contact or by contamination of fomites (Debnath $\mathrm{T}$ et al., 2018). S. aureus is one of the most common causes of HAIs, often of wounds (surgical) or bacteraemia associated with catheters (Morubagal et al., 2017). The isolation of Bacillus spp. (11.56\%) in this study confirms its ubiquitous nature as well as the ability of its spores to resist environmental changes, and with stand dry heat and certain chemical disinfectants for moderate periods (Mushabati et al., 2021). Gram negative organisms were isolated only in $19.72 \%$ cases. Most of the studies Pal et al., (Pal et al., 2015), Sharma et al., (Sharma et al., 2017) done in this field reflect the same. Of the 147 isolates, $38.77 \%$ (57/147) isolates like S.aureus, Enterococcus spp, Pseudomonas sp, E.coli, Klebsiella sp, Acinetobacter sp were established pathogens for hospital associated infections. Though, CoNS is a component of normal skin flora but in hospital set up it could emerge as a pathogen, increasing number of microorganisms causing nosocomial infections. The high isolation of Bacillus, Micrococcus, Diphtheroids in around one fourth cases confirms that these bacteria are omnipresent in nature being able to colonize anything. The presence of E. coli $(2.72 \%)$ and Enterococcus sp (3.4\%) suggest faecal contamination of cell phones also. Of great concern is the isolation of Pseudomonas and
Acinetobacter spp. from the mobile phones of HCWs, as these organisms are known to be multi-drug-resistant healthcare-associated pathogens. Furthermore, the isolation of Acinetobacter spp. on mobile phones in this study is not surprising as they have been isolated from numerous sources in hospital environments in outbreak and non-outbreak settings (Mushabati et al., 2021).

Almost equal rate of contamination was found in the cell phones used by male and female health personnel. But proportion of contamination of mobile phones of male resident doctors was more than female resident doctors in a study by Pal et al., (2015).The warmth of clothing conferred a good breeding ground for the microorganisms mainly Staphylococcus sp, Acinetobacter sp that resist drying. So the warm and cosy environment in the pocket surrounding mobile phones coupled with its regular handling creates a main breeding ground for microorganisms. (Pal et al., 2015). All the 100 HCP used same phones in and outside the hospital. $17 \%$ of health professionals were totally not aware about the fact that cell phones could act as a source of bacteria. 94\% of the participants never even thought of cleaning their mobile phones.

Almost all of the health care workers do not wash their hands after receiving phone calls and before touching patients except 3 persons working in neonatal wards. Almost same picture was revealed in Pal K et al., (Pal K et $a l ., 2015)$ Antibiotic sensitivity pattern of gram positive isolates revealed good sensitivity against Vancomycin and Linezolid. Antibiotic sensitivity pattern of the isolates showed that 6 (24\%) and $11(22.91 \%)$ of Staphylococcus aureus, CONS were resistant to methicillin (MRSA) respectively. 
Table.1 Distribution of bacterial isolated from mobile phones

\begin{tabular}{|c|c|c|}
\hline Bacteria isolated from mobile phones & Number & Percentage \\
\hline CONS & 48 & $32.65 \%$ \\
\hline S.aureus & 25 & $17 \%$ \\
\hline Bacillus sp. & 17 & $11.56 \%$ \\
\hline Micrococcus & 15 & $10.2 \%$ \\
\hline Diptheroids & 6 & 4.08 \\
\hline Enterococcus faecalis & 5 & $3.4 \%$ \\
\hline a haemolytic Streptococcus & 2 & $1.36 \%$ \\
\hline Pseudomonas sp. & 12 & $8.16 \%$ \\
\hline Acinetobacter & 9 & $6.12 \%$ \\
\hline E.coli & 4 & $2.72 \%$ \\
\hline K.pneumoniae & 2 & $1.36 \%$ \\
\hline Non fermenter gram negative & 2 & $1.36 \%$ \\
\hline Coccobacillus & & \\
\hline Total & 147 & 100 \\
\hline
\end{tabular}

Table.2 Relationship of Gender and contamination of phones

\begin{tabular}{|c|c|c|c|}
\hline & Contaminated & Sterile & Percentage of contamination \\
\hline $\begin{array}{c}\text { Female } \\
\mathbf{N = 4 5}\end{array}$ & 38 & 7 & $84.44 \%$ \\
\hline $\begin{array}{c}\text { Male } \\
\mathbf{N}=\mathbf{5 5}\end{array}$ & 49 & 6 & $89.09 \%$ \\
\hline
\end{tabular}

Table.3 Antibiotic sensitivity pattern of Gram positive organisms

\begin{tabular}{|c|c|c|c|c|c|c|c|c|}
\hline $\begin{array}{c}\text { Bacteria } \\
\text { isolated from } \\
\text { mobile } \\
\text { phones }\end{array}$ & E & TE & COT & GEN & CX & CD & LZ & V \\
\hline CONS & $50 \%$ & $77 \%$ & $54 \%$ & $84 \%$ & $76 \%$ & $92 \%$ & $98 \%$ & $100 \%$ \\
\hline S.aureus & $39 \%$ & $81 \%$ & $78 \%$ & $88 \%$ & $77 \%$ & $88 \%$ & $96 \%$ & $100 \%$ \\
\hline
\end{tabular}

Table.4 Antibiotic sensitivity pattern of Gram Negative organisms

\begin{tabular}{|c|c|c|c|c|c|c|c|}
\hline $\begin{array}{c}\text { Bacteria isolated from } \\
\text { mobile phones }\end{array}$ & CTX & CTR & CEP & CIP & AK & IMP & PIT \\
\hline Pseudomonas sp. & $55 \%$ & $45 \%$ & $60 \%$ & $65 \%$ & $76 \%$ & $92 \%$ & $88 \%$ \\
\hline Acinetobacter & $40 \%$ & $35 \%$ & $65 \%$ & $70 \%$ & $71 \%$ & $90 \%$ & $86 \%$ \\
\hline E.coli & $50 \%$ & $55 \%$ & $71 \%$ & $86 \%$ & $73 \%$ & $94 \%$ & $91 \%$ \\
\hline K.pneumoniae & $41 \%$ & $40 \%$ & $67 \%$ & $78 \%$ & $87 \%$ & $92 \%$ & $88 \%$ \\
\hline
\end{tabular}


Incidence of MRSA isolated from cell phones was variable in different geographical areas like $24.3 \%$ by Sharma et al., (2017), 29\% by Walia et al., (2014), 39.13\% by Shah, et al., (2019).Most of gram negative isolates were multi drug resistant. Imipenam and piperacillin tazobactam were most effective antibiotics against them. Variation in antibiotic resistance pattern in different geographic areas or different time frame in same place might depend on antibiotic policy of the hospital at that particular time. MDR bacterial strains could be a result of irrational and unnecessary use of antibiotics. This proves that mobile phones increase the burden of nosocomial infection unless some mandatory guidelines and measures are taken regarding the use and cleaning of phones in a health care setting. This difference on antimicrobial susceptibility compared to other studies might be due to different bacterial strains, hospital environment, empirical treatment practice, use of antibacterial as a prophylactic, easy availability of some drugs without a prescription, dose of the drug, and indiscriminate/prolonged use of common antibiotics. Some reports suggested a correlation of clonal resistance with empirical usage of antibacterial agents. These findings bring to prominence the role mobile phone could play in spreading nosocomial infections or the intervention which limit use of mobile phones during work by health care personnel and maintenance of mobile phone hygiene could have in preventing nosocomial infections (Bodena et al., 2019).

More than ninety percent of cell phones belonging to healthcare personnel harboured potential pathogens including some multidrug resistant strains but health care workers were quite unaware of the fact. As there is paucity of information about suitable mobile disinfection methods that are both effective and at the same time do not damage the mobile phones, restricted use of mobile phones in hospital is to be emphasized. Moreover, hand washing after or before attending a call is to be recommended strictly. Use of headset or ear set during hospital hours might be a good alternative for using hand set. There is an urgent need to educate and stress awareness among the HCWs about the potential role of phones in the transmission of infectious agents in and outside hospital. Infection control committee can step forward to make clear cut guidelines regarding the use of phones in health care setup.

\section{References}

Banawas S, Abdel-Hadi A, Alaidarous M, Alshehri B, Bin Dukhyil A A, Alsaweed $\mathrm{M}$, et al., 2018. Multidrug-resistant bacteria associated with cell phones of healthcare professionals in selected hospitals in Saudi Arabia. Can J Infect Dis Med Microbiol., 2018:6598918.

Bisht M, Kumar M, Solanki H, Kaur T, Umesh, Rawat V. 2018. Microbial Contamination of Mobile Phones of Health Care Providers at a Teaching Hospital in a Hilly North Indian State. Indian Journal of Community \& Family Medicine.,Vol. 4 Issue 01 JanJun:34-39.

Bodena D, Teklemariam Z, Balakrishnan S, Tesfa T. 2019.Bacterial contamination of mobile phones of health professionals in eastern Ethiopia: antimicrobial susceptibility and associated factors. Trop Med Health.,47:15.

Brady R, Wasson A, Stirling I, McAllister C, Damani N. 2006. Is your phone bugged? The incidence of bacteria known to cause nosocomial infection on healthcare workers' mobile phones. J Hosp Infect.,62:123-5.

Chakolwa G, Samutela M T, Kwenda G, Mulundu G, Mwansa J, Hang'ombe B M, et al., 2019. Carriage rate and antimicrobial resistance profiles of Staphylococcus aureus among healthcare workers at a large tertiary referral hospital in Lusaka, Zambia. Sci Afr.,5:e00105. 
Clinical and Laboratory Standards Institute. Performance standards for antimicrobial disk susceptibility tests. Approved standard M2-A10. Wayne, PA: Clinical and Laboratory Standards Institute; 2018.

Datta P, Rani H, Chander J, Gupta V. 2009. Bacterial contamination of mobile phones of health care workers. Indian $J$ Med Microbiol.,27:279-81.

Debnath $\mathrm{T}$, Bhowmik $\mathrm{S}$, Islam $\mathrm{T}$, Hassan Chowdhury M M. 2018. Presence of multidrug-resistant bacteria on mobile phones of healthcare workers accelerates the spread of nosocomial infection and Regarded as a Threat to Public Health in Bangladesh. J Microsc Ultrastruct.,6:1659.

Famurewa O, David O. 2009.Cell phone: a medium of transmission of bacterial pathogens. World Rural Observ.,1:69-72.

Morubagal R R, Shivappa S G, Mahale R P, Neelambike S M. 2017. Study of bacterial flora associated with mobile phones of healthcare workers and non-healthcare workers. Iran J Microbiol.,9:143-51.

Mushabati N. A., Samutela M. T, Yamba K., Ngulube J., Nakazwe R., Nkhoma P., et al., 2021. Bacterial contamination of mobile phones of healthcare workers at the University Teaching Hospital, Lusaka, Zambia. Infection prevention in practice., 3:100126

Pal K Chatterjee M, Sen P, Adhya S. 2015. Cell Phones of Health Care Professionals: A Silent Source of Bacteria. National Journal of Laboratory Medicine.,Oct, Vol 4(4): 3338

Pattnaik S, Dahiya A, Roy R. 2014.Spectrum of microorganisms isolated from mobile phones of general surgeons. International Journal of Scientific and Research Publications., 4(2):1-2.

Ramesh J, Carter A, Campbell M, Gibbons N, Powlett C, Moseley Sr H, et al., 2008. Use of mobile phones by medical staff at Queen Elizabeth Hospital, Barbados: evidence for both benefit and harm. J Hosp Infect.,70:160-5.

Rana R, Joshi S, Lakhani S, Kaur M, Patel P. 2013.Cell phones e homes for microbes. Int J Biol Med Res.,4: 3403-6.

Shah P D, Shaikh N M, Dholaria K V. 2019. Microorganisms isolated from mobile phones and hands of health-care workers in a tertiary care hospital of Ahmedabad, Gujarat, India. Indian J Public Health.,63:147-50.

Sharma K, Najotra D. K, Slathia P, Raina S. 2017. Microbiological flora of cell phones: a reservoir of potential pathogens?. Int $J$ Med Res Rev.,5(02):204-208.

Tagoe D N, Gyande V K, Ansah E O. 2011. Bacterial contamination of mobile phones: when your mobile phone could transmit more than just a call. Webmed Central Microbiology. 2011.

Walia S S, Manchanda A, Narang R S, N. A, Singh B, Kahlon S S. 2014. Cellular Telephone as Reservoir of Bacterial Contamination: Myth or Fact. J Clin Diagn Res..,8(1):50-53.

Washington Winn Jr, Allen S, Janda W, Koneman E, Procop G, Paul Schreckenberger, Gail Woods. Eds. 2006. In: Koneman's Colour Atlas and Text Book of Diagnostic Microbiology. Lippincott, Williams and Wilkins., 6th ed. : 1443-1535.

\section{How to cite this article:}

Arjun Gajananrao Jadhav, Sanjay More and Sandeep Nilekar. 2021. Study on Microbial Contamination of Mobile Phones and their Role in Nosocomial Infections in A Tertiary Care Hospital. Int.J.Curr.Microbiol.App.Sci. 10(10): 558-564.

doi: https://doi.org/10.20546/ijcmas.2021.1010.066 